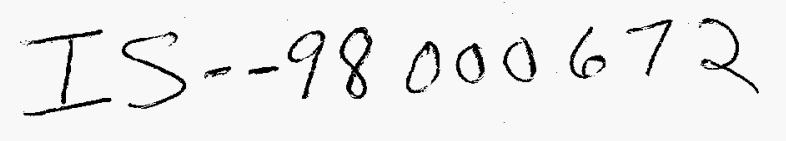

\title{
AMES LABORATORY INTEGRATED SAFETY MANAGEMENT SELF-ASSESSMENT REPORT
}

JUNE 9-13, 1997

\section{RECEIVED \\ SEP 231997 \\ OSTI}

\section{DISCLAIMER}

This report was prepared as an account of work sponsored by an agency of the United States Government. Neither the United States Government nor any agency thereof, nor any of their employees, makes any warranty, express or implied, or assumes any legal liability or responsibility for the accuracy, completeness, or usefulness of any information, apparatus, product, or process disclosed, or represents that its use would not infringe privately owned rights. Reference herein to any specific commercial product, process, or service by trade name, trademark, manufacturer, or otherwise does not necessarily constitute or imply its endorsement, recommendation, or favoring by the United States Government or any agency thereof. The views and opinions of authors expressed herein do not necessarily state or reflect those of the United States Government or any agency thereof.

\section{PERFORMED \\ BY \\ AMES LABORATORY \\ \& \\ CHICAGO OPERATIONS OFFICE \\ UNITED STATES DEPARTMENT OF ENERGY}

DSTRIBUTION OF THIS DOCUMENT IS UNLMTES 


\section{DISCLAMVER}

Portions of this docament may be illegible in electronic image products. Images are produced from the best available original document. 


\section{Ames Laboratory \\ Integrated Safety Management \\ Self-Assessment Report}

June 9-13, 1997

Executive Summary

\section{Introduction}

The implementation of Integrated Safety Management (ISM) at Ames Laboratory began with the signing of the ISM Implementation Charter on February 24, 1997, (see Appendix A). The first step toward implementation of ISM at Ames Laboratory is the performance of a Self-Assessment (SA). In preparation for the SA, a workshop on ISM was provided to the Laboratory's Environment, Safety, and Health (ES\&H) Coordinators, Safety Review Committee members, and the Environment, Safety, Health and Assurance (ESH\&A) staff. In addition, a briefing was given to the Laboratory's Executive Council and Program Directors. Next, an SA Team was organized. The Team was composed of four Ames Laboratory and four Department of Energy-Chicago Operations Office (DOE-CH) staff members (see Appendix B). The purpose of this SA was to determine the current status of ES\&H management within Ames Laboratory, as well as to identify areas which need to be improved during ISM implementation. The SA was conducted by reviewing documents, interviewing Ames Laboratory management and staff, and performing walkthroughs of Laboratory areas. At the conclusion of this SA, Ames Laboratory management was briefed on the strengths, weaknesses, and the areas of improvement which will assist in the implementation of ISM.

\section{Scope}

The team approach of utilizing both Ames Laboratory staff and DOE staff to conduct the SA was intended to assure that this would be a true SA of ES\&H management at the Laboratory and not a DOE oversight audit. The team developed a set of criteria using the seven guiding principles for ISM (see Appendix ()). Using these tools, four subteams were established to review the Ames Laboratory Safety Management System. The SA interviews were conducted with a cross section of the Laboratory's scientific and support personnel to understand the Ames Laboratory ES\&H policies, and their implementation. This SA, and the previously performed DOE-CH Ames Croup SA, have identified the areas which need to be developed and improved before the full implementation of ISM can be accomplished.

\section{Conclusions}

Improvement of ES\&H management of Ames Lahoratory can be traced to shortly before the Tiger Team Assessment. It, was at that time that. Ames Laboratory management recognized the neel to improve its ES\&H systems. The improvements have enhanced ES\&H at the Laboratory and has had a positive influence on the safety of Iowa State University (ISU) research areas. However, no formal mechanism for resolving ES\&H concerns between Ames Lahoratory and ISU currently exist.s. Also, the degree to which 
Ames Laboratory research programs and departments have implemented ES\&H programs vary significantly.

ES\&H roles and responsibilities have been identified but are not effectively communicated and implemented. Documentation concerning ES\&H roles and responsibilities exists in a myriad of documents. The ES\&H Program Manual and the Standard Operations Document (SOD) contain the bulk of the documentation of ES\&H roles and responsibilities. Those documents are outdated and need revision. With some notáble exceptions, not all managers are actively involved in managing the ES\&H functions at Ames Laboratory as inclicated by the inconsistent implementation of ES\&H programs, and the lack of participation by program directors in ES\&H walkthroughs and training programs. The unclear understanding of responsibilities has allowed line managers, in some instances, to defer safety responsibility to the ES\&H Coordinators and Representatives. It was found that employees have little fear of voicing their ES\&H concerns to their management, and that identified concerns are being resolved. Also, there is Laboratory-wide understanding of stop work authority.

The new contract for the operation of the Laboratory is a performance based contract. It has established several high level performance measures in the ES\&H area. Only top Laboratory management and ESH\&A personnel were knowledgeable of the contract's performance measures. The Laboratory has not established any lower tiered goals or measures which can be used to gauge its ES\&H performance. Although ES\&H is included in personnel performance evaluations, no guidance has been given on how to evaluate this element.

ES\&H training at the institutional level is strong and well organized. The Institutional Training Program includes the identification of training needs based on an assessment of each employee. The needs assessment targets mandatory and recommended training modules. The Institutional Training Program also tracks the training individuals have accomplished as well as reminds individuals of renewal requirements. Not all members of the Ames Laboratory staff have participated in the training needs assessment process including some members of senior Laboratory management. Broader baseline training for ES\&H Coordinators and Representatives is also needed.

For new and modified research proposals, the Laboratory has integrated ES\&H review into the Field Work Proposal (FWP) process. The budget process has incorporated aspects of the Readiness Review (RR) process for the identification of ES\&H needs and requirements into new proposals. The Procurement System also has an ES\&H screening mechanism for purchases, including chemicals. However, no process exists which prioritizes or evaluates the ES\&H risks and impacts of proposed capital ungrade projects.

The ES\&H Coordinators and Representatives are effective liaisons between ESH\&A and Laboratory staff. 'This mechanism allows effective communication of ES\&H policy and requirements to staff. However, there are no formal systems for evaluating, communicating, tracking, or trending ES\&H issues, commitments, and lessons learned. Therefore, when deficiencies are identilied or incidlents occur, information is inconsistently communicated. "The Lalouratory has some of the elements of a "Lesson Learned" program but has not combined them into a formal program which will seamlessly assure that pertinent information is consistently convoyed to employees and management. 
The Laboratory has an active Safety Review Committee (SRC) composed of research and support staff. This Committee develops, implements, and directs the RR process. The SRC does not currently communicate directly with the Executive Council/Program Directors on policies and procedures related to all safety issues at the Laboratory. Additionally, the coordination between various ES\&H-related committees needs to improve so Ames senior managers hear one consolidated "voice."

The most notable of the ES\&H programs is the RR process established for new and modified scientific work at the Laboratory. This process establishes a method by which experimental "safety envelopes" are established through a formal review process. RR is effective in identifying and mitigating hazards and is viewed as "value added" by research staff. Although many of the experiments at the Laboratory have gone through RR, approximately $75 \%$ remain in the "grandfathered" category. This has been recognized as a potential problem by the Laboratory's SRC, and work has begun in developing a process which will capture all experimental activities. The corollary is not true for conventional activities, such as support service work. No formal procedures exist that dictate ES\&H reviews must be accomplished and identified issues must be resolved prior to the start of support service work. Also, weaknesses were found in the coordination efforts between facilities engineering and researchers. 


\author{
Ames Laboratory \\ Integrated Safety Management \\ Self-assessment Report
}

June 9-13, 1997

\title{
1.0 Introduction
}

\subsection{Integrated Safety Management Policy DOE P 450.4}

On October 15, 1996, the Secretary of Energy approved DOE P 450.4, "Safety Management System Policy." This Department of Energy (DOE) policy was issued in part in response to the Defense Nuclear Facilities Safety Board (DNFSB) Recommendation 95-2. Recommendation 95-2 calls for the Department to:

1. Establish an institutionalized process for ensuring ES\&H requirements are met.

2. Develop and implement Safety Management Plans for conduct of operations based on risk.

3. Develop a prioritized list of facilities/activities based upon hazard and importance.

4. Promulgate direction and guidance for the ISM.

5. Ensure the Department has, or will acquire, the necessary technical expertise to effectively implement safety management.

In response to these recommendations, the Department established eight commitments in its Implementation Plan for DNFSB Recommendation 95-2 which was issued in April 1996. The "Safety Management System Policy" statement is a response to the first of the recommendations.

\subsection{Ames Laboratory Operating Contract - Performance Measures}

DOE contracts with Iowa State University (ISU) to operate Ames Laboratory. The Chicago Operations Office $(\mathrm{CH})$ provides contractual oversight of Ames Laboratory through the Ames Croup. On December 20, 1996, a new contract was signed for the management and operations of the Laboratory which expires December 31, 1999. This new contract was the result of the contract reform efforts underway within DOE.

This contract is a performance based contract which includes clause language whose intention is improving the overall operation of the Laboratory, as well as increasing the liability which ISU must accept for Environment, Safety, and Health (ES\&H) opcrations. The contract also includes performance award incentives. For ES\&H, only five performance measures have been included which makes up $18 \%$ of the contract performance measures. The irony of this performance based contract is that improved performance by Ames Laboratory 
will reduce the amount of funds available for operations of the Laboratory. This is hecause performance awards paid to ISU for Ames Laboratory's performance are deducted from the Laboratory's research operating budget. Thus, the higher the performance rating the Lahoratory receives, the Ames operating budget is reduced by that amount. A separate award pool source has not been established from which the performance award could be drawn.

The performance measures for ES\&H consist of the following:

1. Employee ES\&H concerns are acknowledged by the contractor within two business days of receipt.

2. Employee ES\&H concerns should be addressed expeditiously.

3. The contractor will minimize reportable injury/illness rates and lost workday case rates.

4. The Laboratory will develop a program to identify chemicals which can be recycled and reused, and recycle those chemicals to the extent practicable.

5. Periodic planned atmospheric and wastewater releases do not exceed regulatory limits and permit conditions.

\subsection{Ames Laboratory Organization}

Ames Laboratory's origination can be traced back to the Manhattan Project. It is unique among the DOE laboratories in that its strengths come from the close affiliation with the faculty and graduate students of ISU. The Laboratory has a variety of individuals who perform work at its facilities. The individuals vary from full time Ames Laboratory employees (hourly and salaried) to graduate students working on degrees above the bachelors level. This mix of individuals who may or may not be employees of the Laboratory provides a challenge in management of ES\&H at Ames.

The Laboratory is organized into an Operations Division and a Science and Technology Division, each reporting to the Laboratory Directorate (see Fig. 1). Research is conducted in any of ten program areas, each of which is headed by a Program Director. The Program Directors have one or more Group Leaders reporting to them. The Ciroup Leaders will have technicians, scientists, and graduate students in their groups. The Program Directors, Group Leaders, scientists, and technicians may be full time Ames Laboratory employees, part time Ames Laboratory empluyees, part time ISU faculty, or strictly ISU faculty. Research can be conducted by Program Directors, Group Leaders, or graduate students. There is a plethora of classifications of Laboratory employees.

Services provided at Ames Lahoratory are performed by Ames Laboratory full time employees. These services vary from maintenance and installation of equipment and facilities to fabrication of various experimental components within the Ames Laboratory Machine Shop. Scientific and engineering research staff at the Laloratory totals noarly 300 , with ahout 120 graduate students comprising a vital part of that total. Tho Laboratory's unique relationship with ISU allows Ames Lahoratory researchers los serve as professors, work with ISU faculty on collahorative projocts, and include gradluater students in Laboratory research. 
This interaction benefits the rescarchers, the students, and the institutions.

\subsection{Self-Assessment}

On February 24, 1997, the DOE Ames (iroup and Ames Laboratory signed a charter for the implementation of ISM at Ames Laboratory. Several activities were required to be accomplished prior to beginning the ISM implementation process. The first item was to assess the status of the ES\&H management systems at the Ames Croup and the Ames Laboratory. (An assessment of ISM for the DOE Ames Group was conducted February 27-March 6, 1997.)

The performance of this Self-Assessment (SA) completes the initial steps in the implementation of ISM at Ames Laboratory. Its purpose is to identify strengths and weaknesses in the systems Ames Laboratory uses to manage ES\&H.

This SA of the ES\&H management systems for Ames Laboratory was conducted during the period June 9-13, 1997. The team which conducted the assessment was made up of four Ames Laboratory staff members and four members of the $\mathrm{CH}$ staff. The criteria used to conduct this SA is attached as Appendix C. The SA was carried out by reviewing documents, conducting walkthroughs, and interviewing members of the Ames Laboratory and Iowa State University staffs. The SA concluded with a presentation to the Laboratory Director, the Executive Council, members of the Environment, Safety, Health and Assurance (ESH\&A) staff, and the SA Team. A description of the process used to carry out the SA, as well as a presentation of the Ames Laboratory safety management strengths and weaknesses, were given. The end result of this SA is the identification of areas in need of improvement to attain full ISM implementation based on the hazards present at Amess Laboratory.

\subsection{Guiding Principles of Safety Management}

2.1 Guiding Principle \#1: Line management is directly responsible for the protection of the public, the workers, and the environment.

Guiding Principle \#2: Clear lines of authority and responsibility for ensuring safety shall be established and maintained at all organizational levels within the Department and its contractors.

\subsubsection{ES\&H Roles and Responsibilities}

ES\&H roles and responsililities for Laboratory management and employees are documented primarily through the Laboratory's ES\&H Program Manual and the Standard Operations Document (SOD). These documents clearly demonstrate management's commitment to ensuring safe operations and protection of the environment. Line management, through policy statiol in the ES\&H Program Manual, and the structure of the organization, has benn given the responsibility for ES\&H at the Laboratory. A sampling of Es\&H programs found clear and well defined 
roles and responsililities idlentified within the ES\&H Program Manual with the exception of the management of subcontractor personnel performing work. While the Laboratory has done an effective job in prescribing roles and responsibilities, not all manigers fully understand their ES\&H roles, responsibilities, and accountabilities. Interviews with both managers and employees, revealed that not all managers are actively involved in managing ES\&H functions. Additionally, not all line managers participate in routine safety inspections or the resolution of safety concerns. In most instances, these duties are deferred to the Croup/Section ES\&H Coordinator/Representative.

The Laboratory lacks a formalized program that identifies clear roles and responsibilities for the management of subcontractors. This does not mean that subcontractor work occurs without any controls. However, without a formal program in place, there is no assurance that individuals understand their roles and responsibilities in assuring subcontractors are performing work in a safe manner. Employees interviewed stated that they were not sure who is responsible for overseeing subcontractor personnel; however if a subcontractor is performing work in an unsafe manner. Ames Laboratory employees stated that they would assure corrective measures are taken.

Resolution of ES\&H issues sometimes involves interaction between Ames Laboratory and ISU. In general, discipline-specific (e.g., Industrial Hygiene, Health Physics) issues related to program implementation are resolved effectively by interaction between the appropriate ES\&H Specialist in each organization. However, resolution of ES\&H issues related to infrastructure have been difficult. One example of this is the resolution of a pedestrian safety issue that involved installation of a sidewalk adjacent to an Ames Laboratory staff parking lot. Another example is recurring indoor air quality/chemical hygiene issues in DOEleased space in Gilman Hall due to an inadequate ventilation system.

\subsubsection{Employee Safety Concerns}

With the exception of the Readiness Review (RR), the Laboratory has informal mechanisms for adjudicating ES\&H concerns/discrepancies among line managers. Employees stated they were comfortable going to their management, or the Lahoratory Safety Review Committee, if they experienced problems that coulul not be resolved at their level. Employees also stated that most discrepancies are resolved at their peer level, and when necessary, their management becomes active in resolving those problems, No examples wore found where ES\&H related disputes were not resolved effectively and efficiently. Laboratory RRs which are primarily performed for new and modified experimental activities, and were found to be an effective means in clarifying issues and resolving disputes. Even though the majority of problems are resolved at the line worker level, when those issues are not rowolved, ESH\& $\Lambda$ is contacted for resolution instead of the employee's management. By empluyeess communicating ES\&H 
problems directly to ESH\& $\Lambda$ for resolution, management is not informed of ES\&H problems. This is a critical element in evaluating employee/manager ES\&H porformance. Senior management needs to be aware of problems and issues that have developed and how they are corrected by line managers. Without, this information, an accurate evaluation of line managors' ES\&H performance cannot, be accomplished.

The Laboratory has created an environment that allows for the reporting and resolution of employee safety concerns. Interviews with personnel revealed that they feel comfortable reporting safety concerns to management without fear of reprisal. Most individuals stated that if their safety concern was not resolved at a lower management level they would seek resolution from ESH\&A. If an issue requires professional support from ESH\&A, the employee's supervisor should be aware of contact with that office. This would result in line management being actively involved and knowledgeable of ES\&H activities in his/her areas. While employees stated that their ES\&H concerns have been adequately addressed, the elements of the program are not documented. This is not necessarily a problem for minor concerns; however, those concerns that require significant resources to correct should be documented to provide an accurate record of assuring that concerns are resolved.

Roles/responsibilities for addressing employee safety concerns also are not documented or understood by all individuals. By maintaining a record of ES\&H concerns, it may be utilized for lessons learned as well as an indicator of how well the program is performing in responding to employee ES\&H concerns.

\subsubsection{External Communication}

The Laboratory Community Advisory Group (CAG) provides an effective forum for external parties to receive information as well as participate in decisions that may have offsite consequences. The CAG grew out of a series of public meeting held at Ames concerning environmental management (EM) work. Recently, the CAG has been useful in disseminating information to Ames residents concerning the clean-up efforts being performed at the Chemical Disposal Site. The community was able to receive current status information of the Site and provide input into the remediation process. The Laboratory also generates an annual Site Environmental Report. (SER) that summarizes environmental activities for that year. DOE-CH reviews and comments on the SER with the final report sent to regulators, political representatives, CAC members, ISU, and other interested parties.

\subsubsection{Internal Communication}

Pertinent, ES\&H information (o.g., ES\&H programs, assessment activities, and external incirlent.s and accidents) is not formally and consistently communicated throughout, the Laboralory. ES\&H information is conveyed 
at: ES\&H Coordinators/liepresentatives meetings. The Laboratory also publishes a monthly newsletier, "Insicler," that is distributed to Laboratory employees. The newslettcer discussoss activities/events occurring at Ames Laboratory, including signilicant, ES\&H events. The newsletter does not typically contain ES\&H information that, would be useful to the Ames programs and groups to obtain lessons learned information. With the exception of major incidents, few employees were aware of accidents/injuries that have occurred at the Laboratory. In the past, ES\&H information was communicated to employees through a lessons learned newsletter distributed by ESH\&A. The lessons learned newsletter was discontinued due to higher ES\&H priorities.

ES\&H performance measures as defined by the contract with DOE have had extremely limited communication to Program Directors, researchers, support staff, and other non- ESH\&A employees. There is no apparent translation of contract ES\&H performance measures to internal goals or objectives at Ames Laboratory. Few Program Directors, researchers or employees, with the exception of ES\&H Coordinators/Representatives and ES\&H professionals, could identify or articulate any internal measurable ES\&H Laboratory goals or expectations. The only goals or expectations expressed during interviews were "to experience no accidents and to comply with DOE ES\&H requirements." Although this is a measurable goal, it is unrealistic, and it does not challenge, benchmark, or impact current individual employee or program performance against future expectations. An example of an effective performance measure would be to complete a specified number of readiness reviews for existing "grandfathered" activities. Another example of an effective performance objective is to provide formal hazard recognition training for all the safety coordinators/representatives. These are examples of goals/objectives that are achievable and measurable and will assist management in effectively evaluating the ES\&H performance of managers and employees.

\subsection{Guiding Principle \#3: Personnel shall possess the experience, knowledge, and abilities that are necessary to discharge their responsibilities.}

\subsubsection{Qualifications}

The Laboratury's ESH\&A stafl possess a broad range of experience and expertise (i.e.. Industrial Salety, Industrial Hygiene, etc.). The staff within this group possess tho appropriate education and experience to effectively support the management of ES\&H activities. ESH\&A personnel can also draw upon the resources available through DOE-CH.

The ES\&H Coorlinator and Representative system is strongly supported by the Laboratory upper management. This commitment is reflected in the level of support provided to thess positions. A percentage of some of the ES\&H Coorlinators' and Representatives' time has been funded by the 
Laboratory Dircetor and l'rogram Directors. The requirements for the necessary skills for hazard illentification have not been formally established for the ES\&H Coordinators and Representatives. While some of these individuals have acquired the basics of hazard identification, others possess a narrower field of ES\&H knowledge. The Laboratory has presented training in the past for ES\&H Coordinators/Representatives to improve their background in hazard recognition. However, this training was discontinued. The Laboratory may accomplish general hazard recognition training by either providing a new training module, or requiring ES\&H Coordinators and Representatives to attend the training related to potential hazards in their areas (e.g., hoisting and rigging or electrical safety).

The Laboratory does not possess a formal process for identifying short-term and long-term ES\&H staffing needs. ES\&H staffing has primarily been driven by budget considerations. Current staffing levels appear to be adequate to manage the ES\&H programs. Budget cuts or new ES\&H initiatives will adversely effect ES\&H performance.

\subsubsection{Training}

All Ames Laboratory employees receive General Employee Training (GET). Job performance requirements are identified and documented via Training Needs Questionnaire (TNQ), Employee Training Needs Profile (ETNP), Hazards Inventory/Job Task Analysis (HI/JTA), Position Information Questionnaire (PIQ), and the Position Description Questionnaire (PDQ). While these documents address different elements of employee job requirements, together they adequately identify job tasks, potential hazards, and required training . Each Laboratory employee is required to have a PIQ or PDQ, and a HI/JTA completed for them by their supervisor. However, not all individuals performing research or work at the Laboratory are Ames Laboratory employees and, thus, may not have a PIQ or PDQ completed for them. The TNQ/ETNP is primarily utilized to determine an individual's training needs; however, the completion of a TNQ is not currently mandated. Approximately $8 \%$ of the Laboratory staff have not completed a $T N Q$, making it impossible to determine whether these individuals have received the alpropriate level of ES\&H training.

The HI/.TTAs are updated on an annual basis or when an employee changes job functions. The Hazard Inventory aids in identifying hazards with which an employee will be working and provides a method for ESH\&A to identify hazard controls and appropriate work site monitoring. The Hazard Inventory is an appropriate and effective tool for identifying hazards to which an employee will he working. However, the Job Task Analysis could be expanded to better identify all potential hazards associated with their jol, activities, rather than just, for Americans with Disabilities Act. (ADA) issues. As currently practiced, the olob Task Analysis is used to determine if an employee can perform all (essential jol, functions, with or without reasonal)le accommodaations, to mect $\triangle \mathrm{DA}$ (criteria. 'The Job Task Analysis 
should complement the larard Inventory by laking this Inventory one step further for hazard analysis. Hayards to which the employee will be working are partially identilied on the Hazard Inventory. However, a Job 'Task Analysis should be uscel to analyze the interactions of the employee with those hazards, the creation of new hazards as a result of those interactions, and hazards in the surrounding areas that may be exacerbated from the job functions. A more comprehensive Job Task Analysis to encompass ES\&H issues, including ergonomic stressors, with the ADA issues would be beneficial.

During a visit to Metallurgy and Ceramics (M\&(C), the New Employee Orientation Procedure was examined. This procedure includes an M\&C Job Hazard Review and an M\&C. Information Packet (which includes such items as an M\&C Organizational Structure for ES\&H Responsibility, information on the Effects of Exposure to Metal Fines and Fumes, Items the Employee Must Be Aware Of, a Chemical Compatibility Chart, a Work Alone Policy, etc.). The M\&C Job Hazard Review and M\&C Information Packet go above and beyond the HI/JTA. This type of information provides an example of things to consider for an expanded Job Task Analysis that can be used site-wide at Ames Laboratory.

The PIQ/PDQs are updated when an individual changes jobs, allowing job safety requirements to be illentified prior to the start of work. An additional means of hazard identification associated with employee job activities is the "Activity ES\&H Hazard Identification Checklist" which is completed as part of the RR process.

ES\&H training for Laboratory employees is provided and coordinated through ESH\&A. The Laboratory also takes advantage of ES\&H training offered by ISU. Individual ES\&H training requirements are determined by the completion of the TNQ which is utilized by ESH\&A to determine core training courses relating to the individual's job tasks and hazards. Each employee's supervisor utilizes the TNQ to identify additional ES\&H training that may be required to perform their jobs. The ETNP identifies mandatory, suggested, and elective institutional training, and is tracked and documented by the Ames Laboratory Training Records System (ALTRS). While the TNQ is a valuable tool for assuring employees receive the appropriate level of ES\&H training, not all employees have completed a TNQ. Without a completed TNQ, there is no means to assure employees are properly trained. Each Program/Croup is required to provide the "onthe-jol" training to assure individuals are properly trained prior to the starti of work. Employee training profiles were reviewed and showed that employees had completed the necessary ES\&H training requirements. The ALTRS system is utilized to notily employees of required training and retraining. The omployoe's (iruup Leader/Section Leader is responsible for assuring the employeos complete training prior to performing any work that requires special Es\&ll training. 
The majority of the lis\&lI training molules are presented by Laboratory subject maltier export.s. (hangess to the training molules are made as a result of changes in regulations, student, feedlsack, and current, events at the Laboratory relating to the subject matier. Several lesson plans were reviewed and found to be comprehensive in the coverage of the subject matter. The training facilities and lesson plans that, were reviewed were found to provide an effective medium for ES\&H training.

\subsection{Guiding Principle \# 4: Resources shall be effectively allocated to} address safety, programmatic, and operational considerations. Protecting the public, the worker, and the environment shall be a priority wherever activities are planned and performed.

\subsubsection{Institutional Plan}

The Ames Laboratory Institutional Plan does not articulate management vision for ES\&H. The document meets the Departmental requirements and guidance for development of institutional plans. However, Departmental requirements have not included any specific guidance on identifying and discussing ES\&H issues in the development of an institutional plan. Therefore, the Ames Laboratory Institutional Plan provides no discussion, insight, or vision for ES\&H performance or expectations for future institutional activities at the Laboratory. It typically discusses past issues and/or achievements in ES\&H and is therefore retrospective.

\subsubsection{ES\&H Documents}

The Ames Laboratory Safety Manual establishes policies, procedures, and guidance for providing adequate protection of the public and employee health and safety as well as the environment. The Ames Laboratory ES\&H policies delineated in the Laboratory ES\&H Program Manual are consistent with and reflect Department policies and expectations for controlling ES\&H hazards. Individual research programs and groups are required by the Ames Laboratory ES\&H Program Manual and the SOD to have policies and procedures that control work hazards and or implement appropriate work controls. Typically, these policies and Standard Operating Procedures (SOPs) comply with the Ames Laboratory ES\&H Program Manual. However, these policies and SOPs vary greatly between and among research groups and programs. In addition, the SOD has become an outdated document, that although reviewed and approved by management, has never been fully implemented.

\subsubsection{Budget Process - Field Work Proposals (FWP)}

One of the ES\&H management strengths at Ames Laboratory is the leadership of the Ames Bulgret Office in integrating ES\&H into the budgeting process. This is a strength because there currently does not exist, in the DOE budgeling process, any vehicle that culls out or makes 
ES\&H activities visible to DOE. The planning and budgeting process implemented by the Ames Budget Office makes effective use of the RR process in the development of all new FWP. The Ames Budget Office, in its "Field Budget and Work Authorization System (WAS) Call," provides guidance and instructions for developing FWPs. In the instructions is the requirement to use the Ames Laboratory "Activity ES\&H Hazard Identification Checklist" (ES\&H checklist) to assure all FWPs have identified and planned for all relevant ES\&H hazards. This ES\&H checklist is also used in the RR process to guide researchers in adequately identifying and addressing ES\&H hazards. The FWP and the ES\&H checklist are then evaluated by the individual research program's Safety Coordinator and reviewed and approved by the appropriate group leader. The FWP is then reviewed by the Office of Planning and Intellectual Property, ESH\&A, and the Ames Budget Office, who has assumed the leadership responsibility for assuring with ESH\&A that all FWPs have identified and addressed all ES\&H issues relevant to the work proposal. This approach helps ensure that all new scientific work proposals have adequately planned for ES\&H issues in the budget. This process is effective for new and modified research activities since those activities undergo a rigorous review as part of a formalized and recognized process (the RR process). However, FWP's are not routinely reviewed by the Operations Office and they are not reviewed by DOE for ES\&H activities or impacts.

It's important to note, that if " $x$ dollars" are requested to fund FWPs, Ames Laboratory in its budget may get back "x minus y dollars." Often the ES\&H activities identified in developing the FWPs will have to be funded out of individual program overhead burden, the Laboratory overhead, or the project is held in full or partial abeyance until adequate funding has been procured. In interviews with the program directors, several projects were discussed in which overhead burden had to be used to fund all relevant ES\&H activities or upgrades. In other instances, specifically in Metallurgy and Ceramics, projects have been put on hold as a result of not being able to adequately fund ES\&H improvements. This clearly demonstrates a commitment to safety by some. Ames Laboratory Program Managers. However, Facility Services budgets, activities, and priorities, have no formal recognized process for identifying, evaluating, and prioritizing ES\&H capital and infrastructure needs. These requests are not formally reviewed for ES\&H impacts, although budget and ESH\&A are consulted. This consultation only occurs at the time of budget submission. The Ames Budget Office provides guidance in developing the overhead budgets for administrative and other support function ES\&H needs. Direction and instruction are provided in the "Budget Call For Administrative and Operating Groups" in early summer. Planning for ES\&H needs and contingencies is developed and documented in the "Incremental Budget Request." Some recognized sources for identifying ES\&H needs when developing the overhead budget are specifically addressed in this guidance and instructions. One of the sources identified 
is tho ES\&H Five-Yoar Pan (ES\&H Management. Plan). A system for capturing and calogorizing all ES\&H vulnerabilities and longer term planning priorities atross tho laboratory does not exist, despite Ames Budget Oftice's FWP developmont process. 'There is no site-wide prioritization process that, occurs for ES\&H, capital, and infrastructure needs.

\subsubsection{ES\&H Management Plan}

The ES\&H Management. Plan requires the use of a specific risk-based prioritization process. However, this process has limited use and is primarily used at Ames Laboratory as a reporting document for DOE, and for prioritizing ESH\&A needs. The ES\&H Management Plan is reviewed by $\mathrm{DOE}$ and is currently the only vehicle in the Department that provides visibility at all levels within DOE for ES\&H activities, expenditures, and needs. Very few Ames Laboratory Program Directors and fewer ES\&H Coordinators are aware that the ES\&H Management Plan exists and could be used to assist in planning and procuring additional funding for ES\&H.

Currently, funding priorities are established through discussions between budget, ESH\&A, and the Laboratory Director. Risk is not established for needs on a systematic basis. Funding for capital and GPP activities are considered based on the Facility Services Manager's current perceived level of need. Long term planning and needs assessment that establish priorities based on clearly defined ES\&H risk reduction potential or formal documented impacts to mission and programs are not done except by ESH\&A. However, this is accomplished in a limited way to reflect operating expenses or issues that are of immediate concern to the budget preparation for the current planning year. In addition, documented roles and responsibilities for conducting annual condition assessments for capital upgrades are nonexistent. Instead, the informal policy is to rely on the discretion of the Facility Services Manager with informal input from staff. This is typically done only in anticipation for the current budget planning year and is therefore reactive.

\subsubsection{Self-Assessment Activities}

The lack of formal systems for documenting, tracking, and trending ES\&H issues, impedes the effective utilization of the results of assessment activities in benchmarking and improving ES\&H performance. Two types of self-assessment activities exist, Program Walkthroughs and Independent Walkthroughs. Both are compliance driven. The Program Walkthroughs are conducted by the Program Safety Coordinators. The Safety Coordinator is typically a researcher who is assigned this responsibility as a collateral duty. Salfety Coordinators are a resouree within the individual programs who assure that program stall, employeses, and students are cognizant of hasic ES\&H requirements. The Independent. Walkthroughs; also called the Quarterly Walkthroughs, aro conducted hy two representatives from 
ESH\&A, the Dopuly Diroctor, the Electrical Inspector, the Assistant Manager for Procurement and Property and the Relevant Program Director and Safet.y Coordinator. Thase walkthroughs provide an external. assossment of the individual programs and look at ES\&H compliance as well as space allocations and e(puipment utilization. The Independent Walkthroughs are seheduled so that all areas of the Laboratory are gone through in a three yoar period.

Weaknesses of the Program Walkthroughs include: Program Director involvement is sporadic or lacking, no basic requirements exist for the ES\&H Coordinator position, ES\&H Coordinators receive no formal training for conducting assessments and/or walkthroughs, and the frequency and rigor vary from Program to Program. Walkthroughs are inconsistent and vary across programs and groups and most have become a "housekeeping" inspection. The Independent, Walkthrough Program has not kept to its planned triennial schedule. Some Program Directors were unaware of the Program.

A significant cause for inadequacies in the Ames Laboratory selfassessment activities and goals, are a result of the Department's transition from formal and frequent ES\&H functional appraisals and oversight to performance based contracts. CH and the Ames Group have not provided clear direction to the Laboratory on what the Department expects in the contractors' Self-assessment Program. In addition, $\mathrm{CH}$ is still struggling over its role in providing effective oversight. This is an evolving issue that will need to be clarified for the Laboratory to implement an SA Program that will be responsive to the needs and mission of the Department.

\subsubsection{Incident Investigation}

No formal policy or system exists to investigate incidents and accidents. Investigation of accidents is clone at the clirection of DOE and/or the discretion of management. Incidents are occasionally investigated at the direction of the Manager of ESH\&A. Currently, the investigation report of a major incident which could have resulted in a fatality has not to date been completed. This incident, occurred approximately 18 month ago.

Root, cause analysis is not routinely accomplished on incidents and accidents. The only analysis which may be conducted using incident and accident information is Lost Work Day Case Rates. Currently, only two ESH\&A staff have formal training in root cause analysis, and one of these individuals is retiring in August.

\subsubsection{Issues Management}

Ames Lalowratory does not have an "Issues Management System" for documonting, evaluating, tracking, and trending ES\&H issues. Also, the lack of a formal lessons Learned P'rugram severely limits the ability of 
management to develop) realistic benchmarks and performance indicators. Amess Laboratory lacks many of the ES\&H Management Information Systems that: would provicle inpul.s to an lssuns Management System. An ESH\&A staff member has been recently appointed to develop a Lessons Learned Program.

\subsubsection{Employee Performance Evaluations}

A formal system of employee performance appraisals is in place for Ames Laboratory employees. Employees are evaluated annually by means of a written performance evaluation procedure and form, the results of which are communicated and discussed with the employee in a meeting with the evaluating supervisor. This performance evaluation includes eleven elements for line workers, including one for ES\&H performance. For supervisors, their supervisory performance is evaluated against six elements, of which one relates to ES\&H supervision. There is a training module for supervisors performing evaluations; however, this module is nonmandatory and does not provide clear guidance for evaluating individual ES\&H performance. One section of the performance evaluation involves the setting of individual goals and objectives for the coming year and these goals and objectives are used in subsequent evaluations. A significant problem with the Employee Performance Evaluation Program is that it is used in a vacuum. That is, with some exception, there are no program, group, or individual performance benchmarks.

Several specific weaknesses in the Performance Evaluation Program were observed:

1. Evaluations are not uniformly performed. P\&S employees are typically evaluated; however, not all ISU faculty who have joint Ames Laboratory appointments or who are Ames Laboratory associates are evaluated.

2. Supervisors are not provided guidance on how to evaluate ES\&H performance or how to weight. ES\&H performance in determining summary ratings.

3. 'There is no obvious connection hetween performance evaluations and salary recommendations. For ISU faculty, salary recommendations are made by their acalemic departments, with varying degrees of input from their Ames Laboratory supervisor. Other employees were found whose evaluations were not performed prior to the deadline for salary recommendations.

4. ES\&H performance was only liound to be an important evaluation element for those employeses with significant collateral ES\&H duties (e.g., Es\&H (oordinalors). 
5. There is no documented or obvious relationship between individual employee performance appraisals and the results of assessment (e.g., walkthroughs, solf-assessisment.s, external assessments) activities at the Laboratory. No instancess were lound of information from the walkthrough or other assossment activities being used by supervisors or Laboratory management to evaluate ES\&H performance of employees, programs, or facilitics.

The above weaknesses in the employee evaluation program are the result of unclear internal performance elements in ES\&H and the lack of a formal lessons learned program to provide feedback to supervisors on ES\&H performance of individuals, group leaders, and program directors.

\subsubsection{Document Control}

A document tracking system is in place at Ames Laboratory that tracks DOE Orders and other types of internal and external documents that can impact Laboratory management. These are documents that management needs to review for its impact on programs, cost, and requirements. This system is supported by ESH\&A but not all managers respond or review the documents. Management commitment in requiring compliance with the document tracking system is lacking.

2.5. Guiding Principle \# 5: Before work is performed, the associated hazards shall be evaluated and an agreed-upon set of safety standards shall be established that, if properly implemented, will provide adequate assurance that the public, the workers, and the environment are protected from adverse consequences.

\subsubsection{Work Smart Standards Process}

Ames Laboratory used the Department's Work Smart Standards (WSS) closure process to identify ES\&H standards and requirements appropriate for the type of work. This process involved Laboratory and DOE personnel in the identification of the standards and requirements that the Laboratory must adhere to in the performance of work. The standards and requirements are consistent with Federal and State requirements for industry. In some instances the selected standards reflect best industry practices and consensus standards. However, not all consensus standards were aclopted. The WSS process took minimal effort in notifying researchers and employess of this process and did little to encourage employee and stakeholder involvement. With some exceptions, few employees were aware of this process that was just recently completed.

The WSS have not been fully incorporated into the Lab's ES\&H policies and procedures. Many policios and procedures have not been updated and still refer to regulations/DOE ()rices that were eliminated as a part of the WSS process. Nlso, the baluratory has not, fully utilized the WSS in clearly 
defining organizationat ES\& H goals and objectives. Contractual language regarding ES\&H performance as defined by performance measures is not fully reflective of the WSS sot requirements.

\subsubsection{Readiness Review Procedure}

Ames Laboratory uses its Roadincsss Review Procedure to evaluate the hazards of new and modified rescarch activities. This is discussed in greater detail within Section 2.6.2 below.

\subsection{Guiding Principle \#6: Administrative and engineering controls to prevent and mitigate hazards shall be tailored to the work being performed and associated hazards.}

\subsubsection{Hazard and Work Controls Identification}

Laboratory has several standing ES\&H-related committees that help the various line organizations and researchers properly identify hazards and appropriate work controls. Paramount in assuring research is conducted with adequate work controls is the Safety Review Committee (SRC). The $\mathrm{SRC}$, in an advisory capacity to the Director, recommends policy and procedures related to safety issues of research and operational activities, including electrical safety. The SRC also develops, implements, and directs an ES\&H Readiness Review Process for all activities under the responsibility and/or control of Ames Laboratory. The SRC has evolved into essentially a "Readiness Review Committee." The SRC is effectively only performing half of its assigned charter duties - developing, implementing, and directing an ES\&H Readiness Review Process. Ames Laboratory personnel, including committee members, readily associated the ES\&H Readiness Review Process with the SRC, but were unaware or unclear as to the other roles chartered for the SRC. The Ames Laboratory Director made it clear that he expected the SRC to advise him on policies and procedures related to all safety issues at the Laboratory.

The SRC charter states that the Committee was formed by the Laboratory Director and serves in an advisory capacity to the Director. Currently, there is no formal and direct communication between the SRC Chair, and the Lalonratory Director/Executivo Council. Instead, information is conveyed to upper management via the Manager, ESH\&A (who is a member of the SR()). 'This call allow for screening of information to meet the needs of the Manager, ESH\&A, and goes against the principles that established the SRC.

Other committees work is more langeted to specific types of hazards or work. The Electrical Silfety (ommitiee (ESC) was established to develop and implement an Electrical Salfely Program within all of the activities. The ESC consures that, re(puiroments of applicable codes and standards are adelressed. 'The ESC alvises the Slie, and the Ames Laboratory Director. 


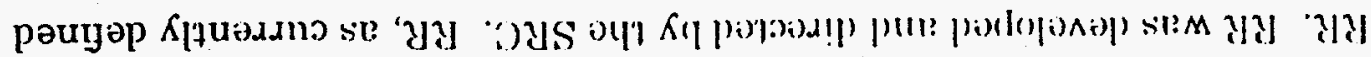

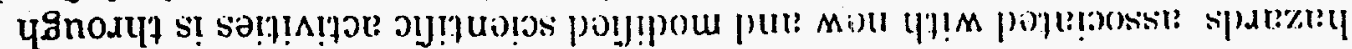

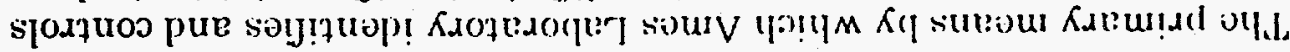

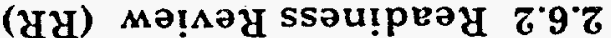

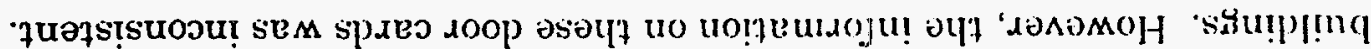

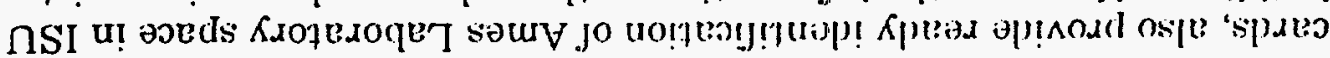

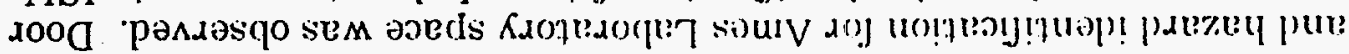

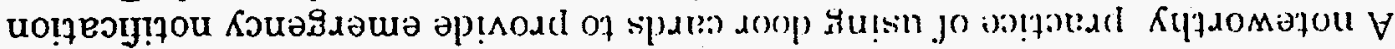

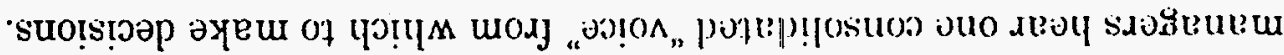

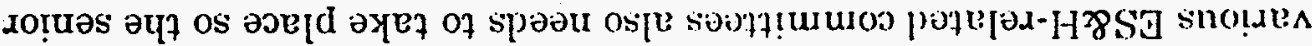

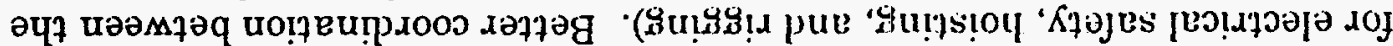

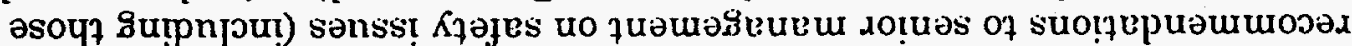

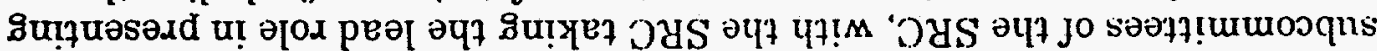

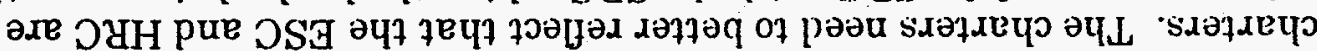

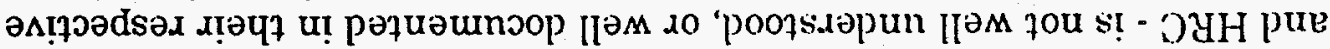

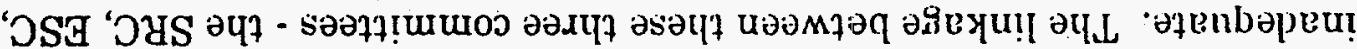

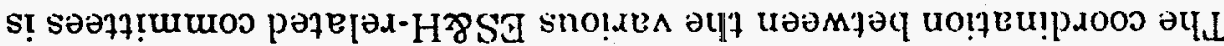

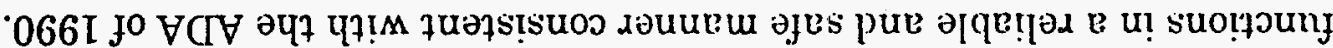

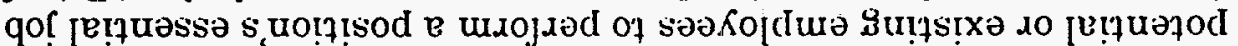

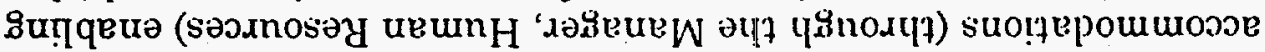

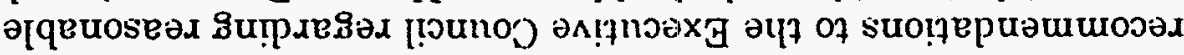

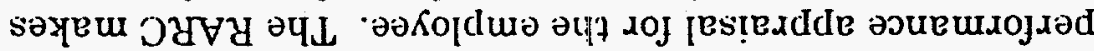

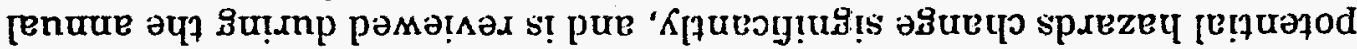

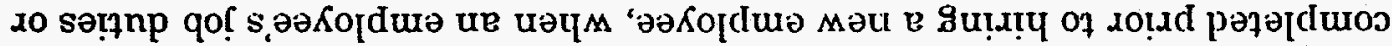

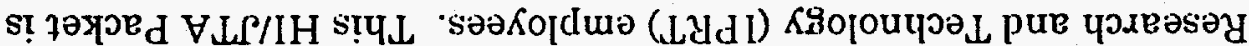

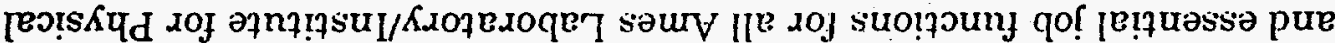

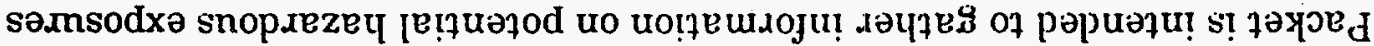

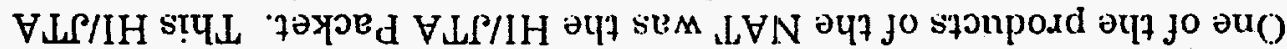

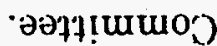

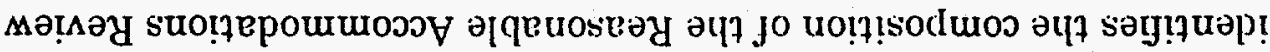

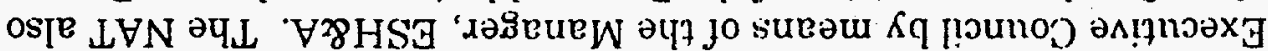

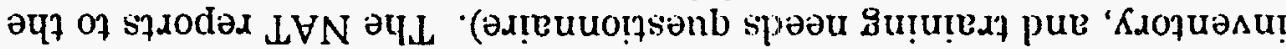

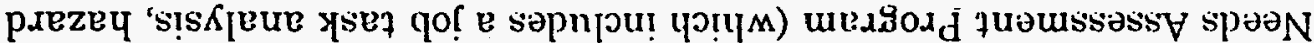

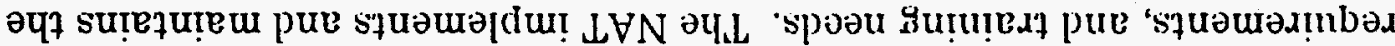

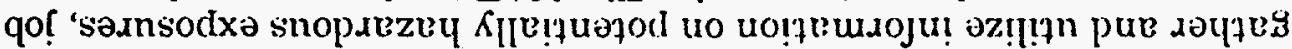

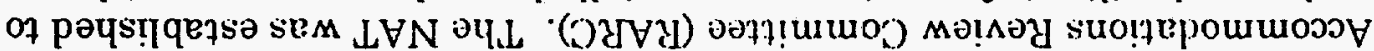

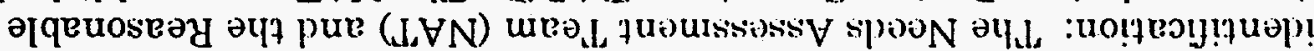

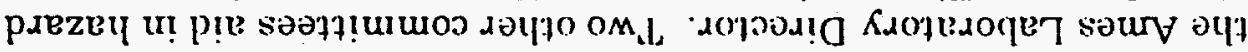

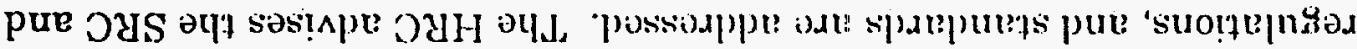

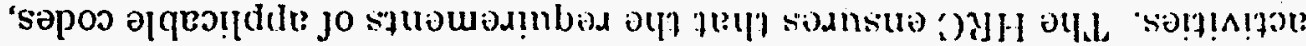

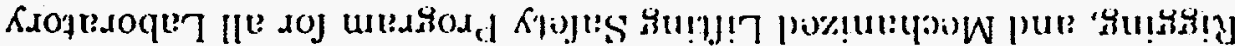
' 8 u!

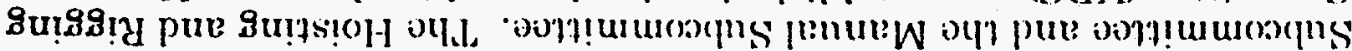

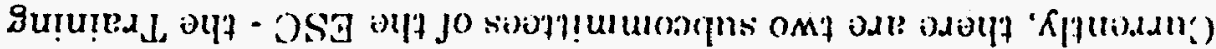


and practiced, is an excellent process for identifying hazards and their controls. In addition, the requirement for $R R$ is incorporated into new research requests. 'This process was viewed as value-arded by interviewees. Employees are aware of the Readiness Review Process, associated the Process with the SRC, and viewed it an effective process.

$R R$ is an effective process for illentilication, mitigation, and control of hazards. 'Through the use of the Activity ES\&H Hazard Identification Checklist and Hazarl Management Statements hazard controls are identified. The approvals and reviows ensure that controls are properly evaluated and implemented. The classification of activities into ES\&H Hazard Level I, II, or III ensures that a graded approach is applied.

However, RR is currently confined to new and modified scientific activities and does not cover existing research and nonscientific activities. The Readiness Review Procedure and the SRC Charter, however, state that RR applies to all activities. The limiting of this process to just new/modified scientific activities results in only a portion (approximately $25 \%$ ) of Ames Laboratory activities having undergone a thorough hazard analysis.

\subsubsection{Stop Work Authority}

The Ames Laboratory Stop Work Authority Policy appears to be understood Laboratory-wide (although it is in need of updating). Stop work authority had recently been used in Metallurgy and Ceramics. Due to the failure of active cooling water, overheating of material in a laboratory ensued. The overheating caused the plastic shielding to melt and give off fumes. The building was evacuated and the situation was assessed. A stop work order was given. Actions surrounding this event are an indication that Ames Laboratory personnel understand their roles in stopping work and that this authority can be, and is used.

It was also clearly communicated that an ES\&H RR would be required to start-up work which comes under a stop work order. Review of the Stop Work Authority Policy and the Readiness Review Procedure confirmed this.

\subsubsection{Procurement}

The Ames Laboratory Prosurement, Qquality Procedure ensures that procured items are reviewed for quality and safety concerns. A "Quality Review" may be requested on the ['urchase Requisition form by checking a box. Orders tutaling $\geq \$ 2500$ are automatically reviewed with some exceptions as noted in the Procedure. Orders totaling $<\$ 2500$ do not need to be reviewed, unless they are (1) pressurized vessels/systems, (2) welded structures/components, (3) stock material to be welded, (4) potential counterfoit parts, or (5) electronic/olectrical revices and/or equipment. ESH\&A has also provided P'rocuroment, with a "List of ES\&H Concerns for Purchasing Reviow" which is useol to scereen purchases. In addition, a "List 
of Acutely Hazardous (Chemicals Not Authorized by Credit Card Purchase" is used by Procurement personnel to identify chemicals which need ESH\&A review.

Inspection and acceptance testing procnsses were reviewed with Engineering Services. Mechanical and/or electrical inspections are performed on received material (if the received material was determined to need a "Quality Check"). This inspection and acceptance testing is sufficient to ensure that purchased items conform to stated requirements, corles, and standards and perform as expected.

\section{Specific Observations for Laser and X-ray Safety}

\subsubsection{Lasers}

All Class IIIb and Class IV lasers are required to undergo a Laser System Hazard Assessment. A Laser System Hazard Assessment is required prior to receiving Developmental Approval, via $R R$, for new or modified Class IIIb or Class IV laser systems. This process is above-and-beyond what is required for a typical ES\&H RR and ensures that Class IIIb and Class IV laser systems have a more comprehensive review. All Class IIIb and Class IV laser systems have had a Laser System Hazard Assessment completed for them. Consideration should be given to include Class II laser systems since Class II lasers can cause injury to the retina of the eye from the direct beam, or certain specular reflections, for other than very brief exposures. Consideration should also be given to include Class IIla laser systems since Class IIIa lasers produce accessible radiation 1-5 times the Class I emission limit for invisible beams or 1-5 times the Class II emission limit for visible beams. The Laser Safety Policy also needs to be updated.

\subsubsection{X-ray Systems}

The Analytical X-ray Safety Policy outlines X-ray safety requirements which must be adhered to by all persons working with analytical X-ray systems. All analytical X-ray systems have been assessed and modified to bring them into compliance with the Analytical X-ray Safety Policy, including installation of shields, barriers, and interlock systems. A process similar to the Laser System Hazard Assessment (discussed above) should be considered for analytical $X$-ray systems. Having a form similar to the Laser System Hazard Assessment for analytical X-ray systems would go above-and-beyond what: is recjuired for a typical ES\&H RR and would help ensure a more comprehensive roview for these systems. The Analytical Xray Safety Policy also noeds to ho updated.

2.7 Guiding Principle \# 7: The conditions and requirements to be satisfied for operations to be initiated and conducted shall be clearly established and agreed upon. 


\subsubsection{Authorization Basis}

Since Ames Lahoratory has no "nuclear" or "accelerator" facilities, the concept of an authorization basis takes on a different meaning. In the Ames Laboratory contract. (Modilication M255 to Contract W-7405-ENG$92)$, it is stated that "...the contract establishes the agreed-upon safety requirements and other operating safety parameters for operations covered by the contract, except where the Contracting Officer notifies that Contractor that a separate Authorization Agreement is necessary..." No separate Authorization Agreement has been required, to-date. Therefore, the contract can be consirlered the ultimate "authorization basis" for Ames Laboratory.

At the contractor level, Health and Safety Plans (HASPs) for remedial projects under the EM-40 Program, and RR Developmental and Operational Approvals can also be considered "authorization bases." Proper review and approvals are performed.

The only authorization basis document comparable to "nuclear" and "accelerator" facilities is the ES\&H Hazard Level III Safety Analysis Document. Currently, there are no Hazard Level III Safety Analysis Documents. However, Ames Laboratory is working on the Hydrofluorination Facility Safety Analysis Document. The Readiness Review Procedure provides Guidelines on what to include in this document. Hazard Level III Documents are approved by the Ames Laboratory Director, and reviewed with the Ames Croup Manager and the ISU ES\&H Manager.

\subsubsection{Ames Laboratory Standard Operations Document (AL-SOD)}

The AL-SOD combines quality assurance and conduct of operations requirements in an integrated system to ensure effective operations. Unfortunately, the AL-SOD is not uniformly implemented at the institutional and the program level and is in need of revision. Some programs/groups had developed their own specific SOD, while others had not developed any program at all. Institutionally, certain elements of the AL-SOD were being implemented, while others have not, especially in regards to continuous quality improvement and quality assurance efforts. The AL-SOD should flow from the institutional level to Program/Department-level and then (iroup-level, each defining specific practices/recuirements thal, expand on the programmatic aspects of the $A L$. SOD.

\subsubsection{Support Services Work}

There is an inlormal process for ovaluating ES\&H issues for support services work. ESH\&A reviows green copies of the Service Order Requisitions. However, there is a lack of a verifiable ESH\&A input prior to 
commencement of work. Under the current, practice, it is conceivable that work could start (e.g. "rush" services) prior to ESH\&A reviewing the Service Order Requisition.

There is no formalized hazard identification of Facilities Services work sites. No formal coordination occurs between Facilities Services and group personnel (e.g., ES\&H Representative). Facility Services can be working in an area or room and be unaware of surrounding hazards. Occupants of the areas where support service work is being conducted are not always aware when the work is being performed and if it will have an impact on their projects.

\subsection{Areas for Improvement}

This section is divided into two categories. The first being areas for improvement which will assist in the implementation of ISM at Ames Laboratory. The second category is the areas which will assist in improving the overall safety program of the Laboratory.

\subsection{ISM Implementation}

Guiding Principle \#1: Line management is directly responsible for the protection of the public, the workers, and the environment.

Guiding Principle \#2: Clear lines of authority and responsibility for ensuring safety shall be established and maintained at all organizational levels within the department and its contractors.

Develop a formal mechanism for resolving ES\&H concerns between Ames Laboratory and ISU.

Develop a formal program that defines ES\&H roles and responsibilities for the selection and management of subcontractor employees performing work onsite.

Assure that line managers are aware of their ES\&H roles and responsibilities and take an active role in managing their ES\&H programs.

Develop a formal Employee Safety Concerns Program, which defines responsibilities for involved personnel.

Estahlish a formal Lessons Loarned P'rogram for communication of ES\&H information across the Site. The program should include criteria that identify the type of information that is relovant to the groups/sections for the prevention of future accidents, as well as pertinont ES\&H information to assure management is informed.

Estahlish lower tierel ES\&H performanen measures other than those the contract require to bo utilizod in evaluating the affectiveness of line management and 
employee involvement.

Guiding Principle \#3: Personnel shall possess the experience, knowledge, and abilities that are necessary to discharge their responsibilities.

Est.ablish hazard recognition training requirements for ES\&H Coordinators and Representatives to assure they possess a general awareniess of the ES\&H hazards present in their areas of responsibility.

Require and ensure that all employees complete a TNQ to assure the required ES\&H training is identified prior to an employee starting their job functions.

Develop guidance for supervisors and managers on how to evaluate individuals ES\&H performance.

Develop a formal process for identifying short-term and long-term ES\&H staffing needs.

Develop a more comprehensive JTA to encompass all ES\&H issues..

Guiding Principle \# 4: Resources shall be effectively allocated to address safety, programmatic, and operational considerations. Protecting the public, the worker, and the environment shall be a priority wherever activities are planned and performed.

Include ES\&H performance and expectations for the future in the Ames Laboratory Institutional Plan .

Revise and more fully implement the Ames Laboratory SOD; continue to revise the ES\&H Program Manual

Develop a formal process for identifying, evaluating, and prioritizing ES\&H capital and infrastructure needs.

Ensure full participation in and implementation of self-assessment activities, such as program walkthroughs by line management.

Develop a formal incident and accident investigation procedure including root cause analysis.

Develop training for supervisors and mangers to provide clear guidance for evaluating individual ES\&H performance.

Devolop a formal coordinated lssuoss Management System.

Guiding Principle \# 5: Before work is performed, the associated hazards shall be evaluated and an agreed-upon set of safety standards shall be established that, if properly implemented, will provide adequate 
assurance that the public, the workers, and the environment are protected from adverse consequences.

Uphate ES\&H policios and procedur(ss so they are reflective of the WSS set in the DOE-ISU contract.

Clearly define organizational ES\&H goals and objectives and communicate this information to all employees.

Guiding Principle \#6: Administrative and engineering controls to prevent and mitigate hazards shall be tailored to the work being performed and associated hazards.

Strengthen the SRC role in defining and communicating ES\&H policies and expectations to all levels of the organization (a direct information flow from the Laboratory's SRC to the senior managers). Also, clearly establish the roles of the ESC and HRC as subcommittees of the SRC.

Define a process by which grandfathered activities and associated ES\&H concerns are identified, prioritized as to risk, and reviewed via a procedure comparable to RR.

Guiding Principle \# 7: The conditions and requirements to be satisfied for operations to be initiated and conducted shall be clearly established and agreed upon.

Develop a formal verification process by which ESH\&A reviews are conducted on Facilities Services and Engineering Services Work Orders, including issues resolution, prior to commencement of work.

\subsection{Safety Program Improvements}

Guiding Principle \#6: Administrative and engineering controls to prevent and mitigate hazards shall be tailored to the work being performed and associated hazards.

Stanclardize the quality of the door card information and include a periodic review of the information presented on the door cards.

Update the Ames Laboratory Stop Work Authority Policy.

Consider developing an X-ray System Hazard Assessment similar to the Laser System Hazard Assessment. and uplating the Analytical X-ray Safety Policy.

Consider including Class 2 and ia liasers in the Laser Hazard Assessment. 


\section{AMES LABORATORY Organization}

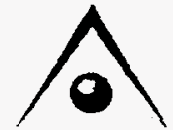

AMES LABORATORY

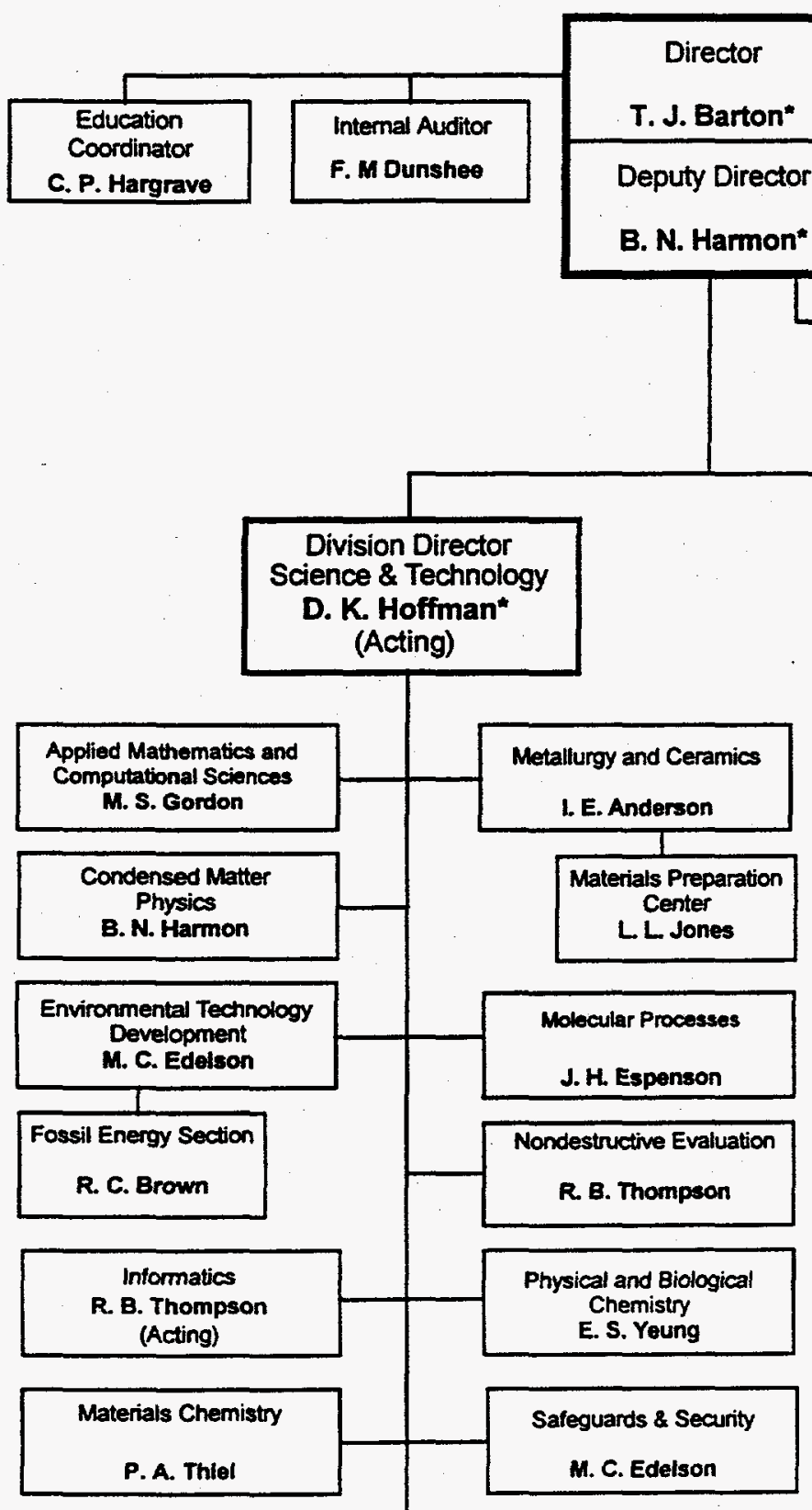

Representatives to Interlaboratory Committees

1. E. Anderson

Partnership for a New Generation of Vehides
. Andorion

M. C. Edalson

Stratogic Lab Council

Laboratory Coordinating Council (OT)
Engineering Services

D. D. Bluhm

Division Director

Chief Operations Officer

M. L. Murphy* (Acting)

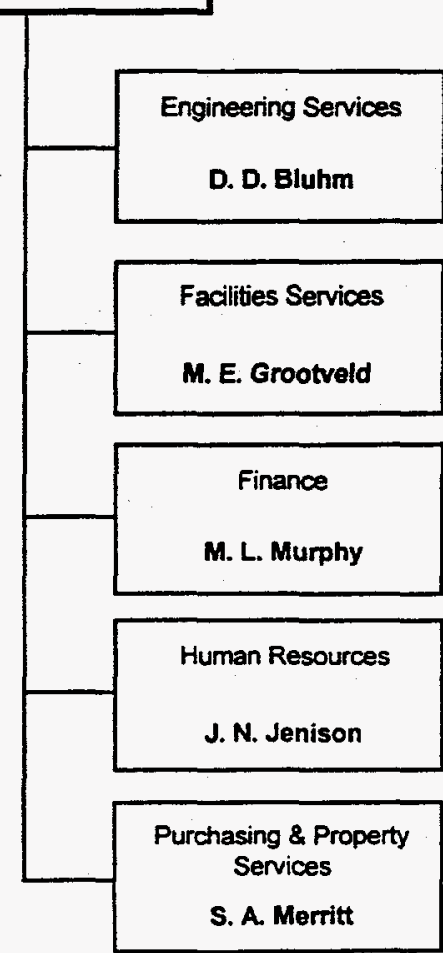

- Member of Executive Council 

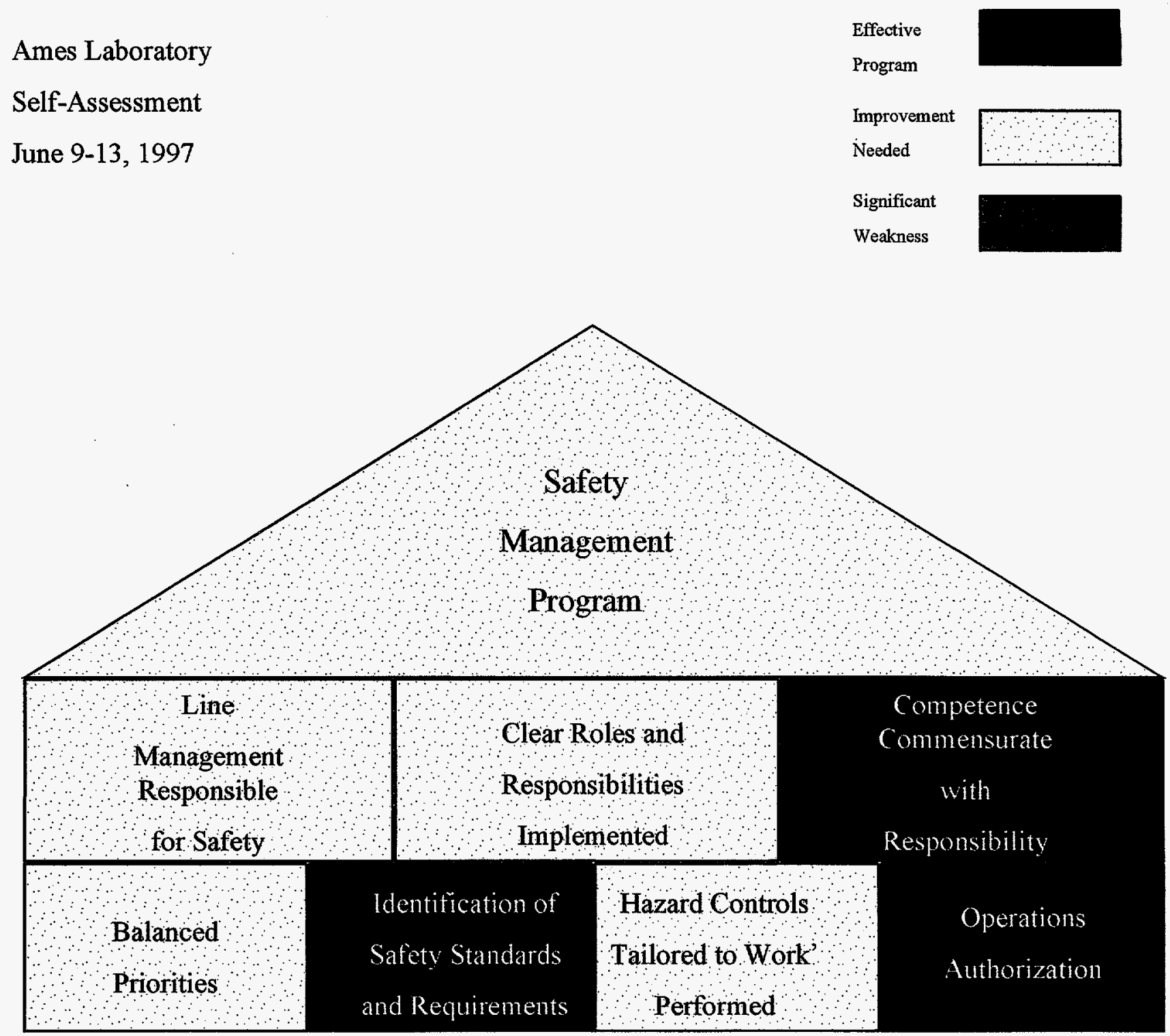

Ratings

Figure 2 


\section{INTEGRATED SAFETY MANAGEMENT (ISM) IMPLEMENTATION CHARTER}

This charter initiates the implementation of the Integrated Safety Management Process for the Ames Group and Ames Laboratory. An ISM Steering Committee will be formed to oversee the entire implementation process. General functions will include designating functional experts as team members, scheduling an ISM orientation for Ames Laboratory staff, preparing a tentative schedule for implementation, and concurrence on assessment plans. Oversight functions will include the oversight of assessments, transition plans, Laboratory's documented system, review/validation of Laboratory's documented system, and conflict resolution. If conflict resolution cannot be attained by this Committee, the Ames Group Manager and Ames Laboratory Director will make the final judgment.

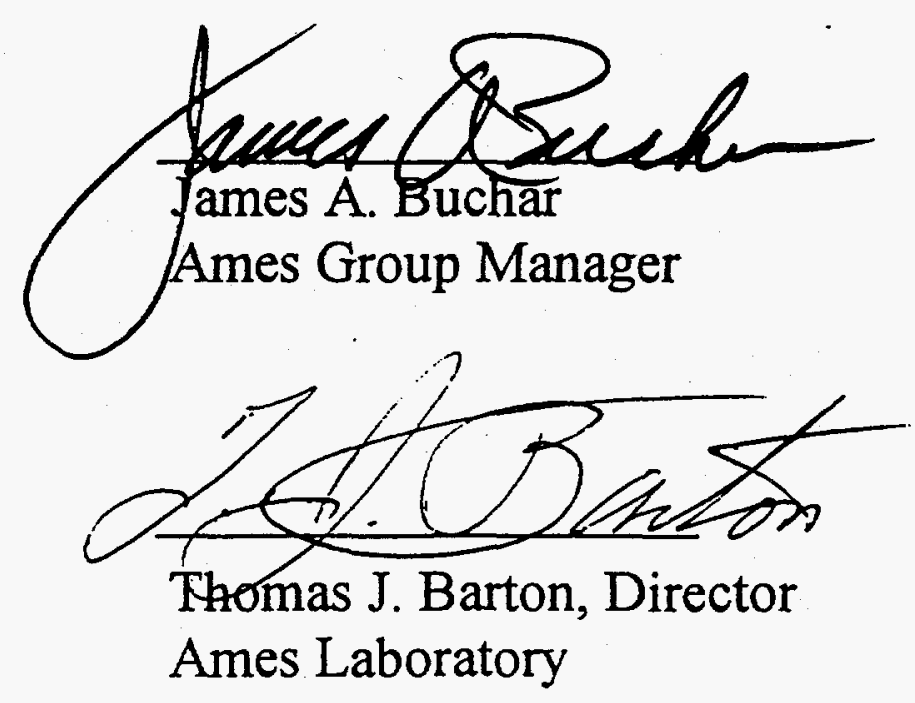




\section{ISM STEERING COMMITTEE:}

Stephanie A. Chesney

Ames Group

Tom E. Wessels

ESH\&A Manager

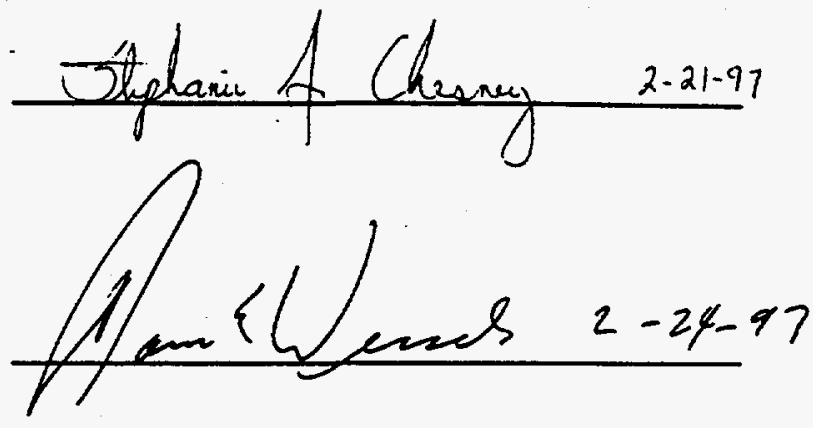

Ames Laboratory

John Adachi

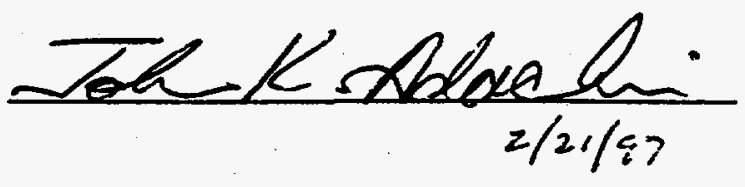

Technical and Administrative

Services Group 


\section{Ames Laboratory \\ Integrated Safety Management Self-Assessment}

\section{Self-Assessment Team:}

$\begin{array}{lll}\text { Co-Leaders: } & \text { James Withers } & \text { Ames Laboratory } \\ & \text { Justin Zamirowski } & \text { DOE-CH-STS }\end{array}$

Team Members: $\quad$ Paul Waters Ames Laboratory John Hayes Ames Laboratory

Tom Lograsso ames Laboratory John Scott DOE-CH-STS

Jon Neuhoff DOE-CH-New Brunswick Laboratory

Tom McDermott DOE-CH-STS

\section{Assigned Areas of Review:}

Roles and Responsibilities -

Work Scope, Planning, and Prioritization

Competence

Hazard Analysis and Standards/Requirements Identification

Hazard Controls and Authorization Basis

Work Performance

Feedback and Improvement
P. Waters/J. Scott

J. Hayes/T. McDermott

P. Waters/J. Scott

J. Withers/J. Zamirowski

T. Lograsso/J. Neuhoff

T. Lograsso/J. Neuhoff

J. Hayes/T. McDermott

Team Member Phone Nos., Fax Nos., and E-mail addresses:

Justin T. Zamirowski PH: (630) 252-2248 FAX: 630) 252-2835 justin.zamirowski@ch.doe.gov

John Scott $\quad$ PH: (630) 252-2380 FAX: (630) 252-2835 john.scott@ch.doe.gov

Jon Neuhoff

PH: (630) 252-2492 FAX: (630) 252-6256 jon.neuhoff@ch.doe.gov

Thomas McDermott PH: (630) 252-2303 FAX: (630) 252-2835 thomas.mcdermott@ch.doe.gov

Jim Withers

PH: (515) 294-4743 FAX: (515) 294-2155 withers@ameslab.gov

Paul Waters

PH: (515) 294-7923 FAX: (515) 294-2155 waters@ameslab.gov

Thomas Lograsso

PH: (515) 294-8425 FAX: (515) 294-8727 lograsso@ameslab.gov

John Hayes

PH: (515) 294-4872 FAX: (515) 294-5204 jmhayes@iastate.edu 


\title{
INTEGRATED SAFETY MANAGEMENT
}

\author{
SELF ASSESSMENT CRITERIA
}

\section{ROLES and RESPONSIBILITIES}

ISM Principle - Line Management Responsibility for Safety: Line management is directly responsible for the protection of the public, the workers, and the environment.

ISM Principle - Clear Roles and Responsibilities: Clear and unambiguous lines of authority and responsibility for ensuring safety shall be established and maintained at all organizational levels within the Department and its contractors.

\section{Assessment Elements:}

- Management is characterized by clear and well-documented lines of authority and responsibility within the organization and the line organizations. Managers have sufficient organizational stature and authority to effectively implement policy and make decisions.

- Roles, responsibilities, and accountabilities are clearly defined, documented, communicated, and understood by all personnel whose activities may impact performance.

- Mechanisms are established throughout the line organization for adjudicating disputes between line managers where discrepancies exist between work goals and management needs.

- A program is in place for communicating with external parties such as regulatory agencies, public interest groups, and the local community to provide them with information and the opportunity to be involved in key decisions.

- Formal and informal channels of communication are in place to effectively communicate information throughout the organization (top-down, bottom-up, and lateral).

- Line management has developed and implemented effective systems to evaluate and ensure the achievement of organizational goals and objectives.

- There is a program to identify, report, and resolve employee concerns. Employee concerns are acted upon, and resolution is communicated to the individual who identified the concern, in a timely and satisfactory manner.

- Management has established an environment in which employees feel free to express ES\&H ideas and/or concerns without fear of retribution. 


\section{WORK SCOPE, PLANNING, and PRIORITIZATION}

ISM Function - Define the Scope of Work: Missions are translated into work, expectations are set, tasks are identified and prioritized, and resources are allocated.

ISM Principle - Balanced Priorities: Resources are effectively allocated to address safety, programmatic, and operational considerations. Protecting the public, the workers, and the environment is a priority whenever activities are planned and performed.

\section{Assessment Elements:}

- Line management has a system to establish and maintain policies that define goals consistent with Departmental policies, organizational mission, and applicable industry standards. ES\&H policy is reflected in facility and activity level manuals, procedures, instructions, etc.

- There is a formal process to establish objectives and targets for performance throughout the organization that includes the periodic review and adjustment of the objectives and targets.

- Management policies and practices demonstrate a strong commitment to a safe and high quality operation and emphasize safe work practices.

- Planning and budgeting are fully integrated in the site's strategic and institutional plans and in the long-term plans and budgets of the DOE field element and CSOs.

- A formal planning and budgeting prioritization process is in place that implements policy, addresses identified risks, and mitigates those risks through the appropriate allocation of resources. ES\&H policy and goals are reflected in funding and budget prioritization decisions.

- Funds for capital, operating, and maintenance projects and programs are allocated and spent in accordance with the organization's policy and risk reduction goals.

- ES\&H policies and goals are effectively communicated to workers.

- ES\&H policies and goals are effectively and contractually communicated to the Laboratory's subcontractors. Laboratory management ensures that subcontractors understand and accept the site's ES\&H policies and goals prior to working. 


\section{COMPETENCE}

ISM Principle - Competence Commensurate with Responsibilities: Personnel possess the experience, knowledge, skills, and abilities that are necessary to discharge their responsibilities.

\section{Assessment Elements:}

- Management has an effective process for determining and addressing short-term and long-term ES\&H-related staffing needs.

- There are effective mechanisms for developing staff with key responsibilities.

- Job performance requirements are identified and documented, and are reflected in the content of the training program.

- Job task analysis, or an equivalent process, is effectively utilized to determine the hazards associated with the job, the skills necessitated by the job, the controls necessary to mitigate the job-related hazards, and the training the worker needs to perform his/her assigned tasks. A process exists for periodically re-assessing job task analyses to determine if the additional training or hazard mitigation controls are needed.

- Training program materials identify and promote the knowledge and skills needed by trainees to perform assigned tasks and maintain or improve performance.

- Training is conducted in the setting most suitable for the content. Training is consistently and effectively presented using approved lesson plans and other training guides.

- Staff resources are sufficient to effectively develop and implement the work, and achieve its performance goals.

- Personnel have the relevant background and qualifications to carry out responsibilities.

- Individual trainees are examined/evaluated regularly and consistently to ensure that learning is taking place and that trainees are acquiring the knowledge and skills required to work efficiently and safely.

- A systematic evaluation of training effectiveness and its relation to on-the-job performance is used to ensure that the training program conveys all required skills and knowledge. 


\section{HAZARD ANALYSIS and STANDARDS/REQUIREMENTS IDENTIFICATION}

ISM Principle - Identification of Safety Sitandards and Requirements: Before work is performed, the associated hazards are evaluated and an agreed-upon set of safety standards and requirements are established which, if properly implemented, provide adequate assurance that the public, the workers, and the environment are protected from adverse consequences

ISM Function - Analyze the Hazards: Hazards associated with the work are identified, analyzed and categorized.

\section{Assessment Elements:}

- A process is established to identify and analyze the hazards associated with the work; this is applicable to all work-related hazards - not only nuclear and radiological hazards. The process provides for re-evaluation of hazards, as appropriate, as the work evolves.

- Workers are actively involved in identifying hazards associated with their work.

- A process is established that ensures standards/requirements, and revisions thereto, are evaluated for applicability and implemented as necessary.

- The standards/requirements identification process employed by the Laboratory recognizes and accounts for the linkage between the work, the workers, the hazards, and the standards and requirements selected to govern the work.

- A process is established for DOE to convey/transmit, to the Laboratory, the appropriate standards and requirements. A process is in-place to ensure such standards and requirements, and revisions thereto, are incorporated into the Laboratory's contract.

- Rules and regulations, DOE Directives, as well as best management practices have been identified.

- Issues management and corrective action processes have been established and implemented to resolve safety issues, noncompliances or deficiencies with rules (Federal/State/local) and standards, and DOE Orders. 


\section{HAZARD CONTROLS and AUTHORIZATION BASIS}

ISM Function - Develop and Implement Hazard Controls: Applicable standards and requirements are identified and agreed-upon, controls to prevent/mitigate hazards are identified, the safety envelop is established, and controls are implemented.

ISM Principle - Hazard Controls Tailored to Work Being Performed: Administrative and engineering controls to prevent and mitigate hazards are tailored to the work and associated hazards being performed. The contractor develops the facility's authorization basis, which establishes the safety envelop for facility operations and activities, and defines what will have to be done to control safety of the operation.

ISM Principle - Operations Authorization: The conditions and requirements to be satisfied for operations to be initiated and conducted shall be clearly established and agreed-upon.

\section{Assessment Elements:}

- There are formal processes to assess operational hazards/risks and to develop plans to mitigate risks and ensure that policy, goals and objectives, including quality assurance, are attained.

- Hazard controls include, as appropriate, engineered and administrative controls appropriate to the work and its associated hazards.

- The process includes worker involvement in developing hazard control/mitigation provisions.

- Configuration management controls have been implemented to ensure adherence to all applicable requirements.

- The authorization basis is clearly defined, and analysis conclusions and requirements are consistent.

- The authorization basis documents are maintained current and accurate.

- A program to identify and address unreviewed safety questions (USOs) is maintained for nuclear facilities. 


\section{WORK PERFORMANCE}

ISM Function - Perform Work within Controls: Readiness is confirmed and work is performed safely.

\section{Assessment Elements:}

- Activities are performed within the bounds of the safety envelope as defined by the authorization basis.

- Safety structures, systems, and components are identified, operated, and maintained consistent with the nuclear, radiological, and environmental consequences of failure as defined by the authorization basis.

- Requirements are effectively translated into site and facility-specific policies, programs, and procedures.

- The facility has established and implemented a program for development, approval, use, and control of procedures to implement policies.

- Formal processes are in place to manage and control documents and records.

- There is a system to ensure work activities are planned and conducted under suitably controlled conditions and in consideration of all potential hazards.

- Processes exist to solicit and incorporate worker input during work planning.

- Measures have been implemented to ensure that purchased items and services conform to stated requirements, codes, and standards, and that they perform as expected.

- A process exists for stop-work and work-restart authorization, and the circumstances associated with its application are clearly defined. Management and staff understand the process.

- A process is in-place to ensure that conditions and requirements have been appropriately identified and achieved prior to starting or resuming operations of work activities at all levels and complexities.

- Appropriate and effective quality assurance, conduct of operations, and maintenance programs are being implemented. 


\section{FEEDBACK and IMPROVEMENT}

ISM Function - Provide Feedback and Continuous Improvement: Feedback information on the adequacy of controls is gathered, opportunities for improving the definition and planning of work are identified and implemented, line and independent oversight is conducted, and if necessary, regulatory enforcement actions occur.

\section{Assessment Elements:}

- Line management has developed and implemented effective systems to evaluate and ensure the achievement of individual goals and objectives.

- A program of performance appraisal has been established throughout the line organization that has as its objectives determining that policies and requirements are appropriately interpreted and implemented; evaluating the effectiveness of requirements and their implementation; and providing management with information on performance.

- DOE and DOE contractor line management have implemented a root cause analysis program to ensure that the underlying reasons for deficiencies are identified and addressed, and a lessons learned program to ensure that those deficiencies are not repeated.

- A program is in place to identify, measure, trend and report performance indicators to provide early identification of potential and operational problems or changing conditions.

- A formal process is established by DOE to evaluate the performance of the site contractor with respect to contractual requirements for the purpose of determining compliance with the contract and any award fee or other incentive. This process is an adjunct to the formal ES\&H oversight and appraisal program.

- A formal system is in place to investigate, report, and monitor trends in incidents and occurrences.

- Planned and periodic internal assessments by line organizations are conducted to measure quality and process effectiveness and promote improvement.

- A self-assessment program has been established to identify and characterize issues at all organizational levels.

- Rules, DOE Orders and standards, noncompliances, compliance schedule agreements, exemption requests, and compensatory measures are formally reviewed and adequately controlled. 